\title{
MODEL KNOWLEDGE MANAGEMENT SYSTEM PADA PERGURUAN TINGGI DENGAN STRUCTURAL EQUATION MODELLING (SEM)
}

\author{
Ni Luh Ayu Kartika Yuniastari Sarja \\ Program Studi Sistem Informasi \\ STIKOM Bali \\ yuni@stikom-bali.ac.id
}

\begin{abstract}
Knowledge management system (KMS) is an information system that supports knowledge management activities. In universities, KMS is very necessary to facilitate access and utilization of knowledge that has been stored in the system of both organizational and unit knowledge. In order for the implementation and management of KMS in higher education to run well, a guideline is needed which is used as a reference for the academic community. These guidelines can be made in the form of a model. build a KMS model and test the model that has been built. This knowledge management system model was built to provide a more complete understanding of the utilization of knowledge management systems in higher education. To find out the compatibility in the implementation of the model with the real environment, a test of the model was carried out. Testing is done so that the model is in accordance with environmental conditions. Testing is done using the Structural Equation Modeling (SEM) model. The research method used refers to the information system research framework. The results of this study can be concluded that the KMS model in higher education consists of three constructs, namely regulation, KMS and strategy. In the KMS construct, there are construct elements, namely process, people and software. The results of the model evaluation show that the regulatory constructs and strategies have a significant influence on KMS.
\end{abstract}

Keywords: KMS model, testing, SEM, university

\begin{abstract}
ABSTRAK
Knowledge management system (KMS) adalah sebuah sistem informasi yang mendukung kegiatan pengelolaan pengetahuan. Pada perguruan tinggi, KMS sangat diperlukan untuk memudahkan akses dan pemanfaatan pengetahuan yang telah disimpan dalam sistem baik pengetahuan organisasi maupun unit. Agar penerapan dan pengelolaan KMS dalam perguruan tinggi dapat berjalan dengan baik diperlukan sebuah pedoman yang dijadikan acuan civitas akademika. Pedoman tersebut dapat dibuat dalam bentuk model. membangun model KMS dan pengujian terhadap model yang telah dibangun. Model knowledge management system ini dibangun untuk memberikan pemahaman yang lebih utuh mengenai pemanfaatan knowledge management system dalam perguruan tinggi. Untuk mengetahui kecocokan dalam implementasi model dengan lingkungan nyata, maka dilakukan pengujian terhadap model tersebut. Pengujian dilakukan agar model sesuai dengan kondisi lingkungan. Pengujian dilakukan menggunakan model Structural Equation Modelling (SEM). Metode penelitian yang digunakan mengacu pada information system research framework. Hasil dari penelitian ini berupa dapat disimpulkan bahwa Model KMS pada perguruan tinggi terdiri dari tiga konstruk yaitu regulasi, KMS dan strategi. Pada konstruk KMS, terdapat elemen konstruk yaitu proses, people dan software. Dari hasil evaluasi model menunjukkan bahwa konstruk regulasi dan strategi memiliki pengaruh signifikan terhadap KMS.
\end{abstract}

Kata kunci: model KMS, pengujian, SEM, universitas 


\section{PENDAHULUAN}

Knowledge management system (KMS) adalah sebuah sistem informasi yang mendukung kegiatan mulai dari penciptaan, penyimpanan, transfer, pengambilan dan penggunaan pengetahuan [1]. KMS telah banyak dimanfaatkan oleh berbagai organisasi dikarenakan banyak orga-nisasi mulai sadar bahwa pengetahuan meru-pakan aset penting dalam organisasi. Selain itu pengetahuan menjadi salah satu keunggulan kompetitif organisasi.

Dalam organisasi yaitu perguruan tinggi, KMS sangat diperlukan untuk memudahkan akses dan pemanfaatan pengetahuan yang telah disimpan dalam sistem baik pengetahuan organisasi maupun pengetahuan unit. Pengetahuan yang terdapat pada perguruan tinggi yaitu pengetahuan terkait perkuliahan, pengetahuan pengelolaan kegiatan, pengetahuan proses bisnis unit, dan kelompok kerja. Selain itu, dalam perguruan tinggi banyak sumber pengetahuan yang berasal dari penelitian dosen maupun mahasiswa.

Agar penerapan dan pengelolaan KMS dalam perguruan tinggi dapat berjalan dengan baik diperlukan sebuah pedoman yang dijadikan acuan civitas akademika. Pedoman tersebut dapat dibuat dalam bentuk model. Daellanbach (1995) mendefinisikan model sebagai penggambaran, menjelaskan, memperkirakan dan memproyeksikan karakteristik struktur atau perilaku fungsi suatu sistem (alami maupun buatan manusia). Bisa juga sebagai abstraksi dan simplifikasi suatu realitas melalui penggambaran karakteristik penting dari situasi nyata (problem situation). Tujuan dari model adalah sebagai pola ataupun alat yang membantu untuk kerangka berpikir, komunikasi, prediksi, pengen-dalian dan latihan serta pendidikan. Sedangkan manfaat dari model adalah untuk meminimumkan kejadian yang tidak diinginkan, mampu melihat kompleksitas, meminimumkan dampak negatif, mampu mengikuti perubahan dan dapat meminimumkan penalaran intuitif [2]. Oleh karena itu pada penelitian ini dilakukan pembangunan model KMS dan pengujian terhadap model yang telah dibangun. Model knowledge management system ini dibangun untuk memberikan pemahaman yang lebih utuh mengenai pemanfaatan knowledge management system dalam perguruan tinggi. Pada penelitian sebelumnya, telah dilakukan analisis mengenai KMS dalam perguruan tinggi dan menghasilkan konstruk pembentuk model yaitu people, regulasi, strategi, proses dan teknologi. Konstruk ini yang akan dijadikan sebagai dasar dalam pembangunan model.

Untuk mengetahui kecocokan dalam implementasi model dengan lingkungan nyata, maka perlu dilakukan pengujian terhadap model tersebut. Pengujian dilakukan agar model sesuai dengan kondisi lingkungan. Selain itu lebih mudah untuk diterapkan. Hasil dari pengujian model ini disebut dengan model respesifikasi atau model yang sudah siap diterapkan dalam perguruan tinggi. Terdapat beberapa tools atau metode dalam pengujian model. Dalam penelitian ini memanfaatkan model (Structural Equation Modelling) SEM dalam melakukan pengujian model KMS pada perguruan tinggi. Pemilihan model SEM ini dikarenakan model SEM melakukan pengujian terhadap kecocokan atau Goodness Of Fit (GOF). Dengan adanya model ini dapat dijadikan acuan dalam perguruan dalam pengelolaan pengetahuan serta dalam penerapan knowledge management system. Selain itu dengan adanya penerapan knowledge manage-ment system pada perguruan tinggi, maka pengetahuan akan tersimpan pada organisasi dalam media sistem informasi sehingga dapat dengan mudah diakses apabila organisasi atau-pun individu membutuhkan.

\section{LANDASAN TEORI \\ Penelitian Terkait}

Penelitian mengenai KMS telah banyak dilakukan. Penelitian yang dilakukan oleh Nur, dkk (2010) mengembangkan model knowledge managament system berupa prototipe sistem yang berbasis web ini menggunakan teknologi semantic web dengan penerapan ontologi serta menggunakan web 2.0 sebagai media untuk kolaborasi antara sesama knowledge worker [3]. Penelitian yang dilakukan oleh Sundari (2014) membangun Knowledge management system Berbasis Website Pada Instalasi Elemen Bakar Eksperimental PTBN Serpong Tangerang Selatan. Knowledge management system dapat memudahkan, kecepatan dan ketepatan web terhadap permasalahan-permasalahan yang sering terjadi dalam penyebaran pengetahuan 
[4]. Penelitian dilakukan oleh Safriadi, dkk (2015) mengimplementasikan Knowledge management system dalam sebuah aplikasi WikiPeat untuk memetakan hasil penelitian dosen, mengum-pulkan dan me-recycle pengetahuan secara terstruktur, mengorganisasi dan mendoku-mentasikan pengetahuan, melakukan agregasi dokumen hasil penelitian berdasarkan PIP dan RIP, serta menyusun dan membuat link sumber-sumber ilmu eksternal[5].

Penelitian yang dilakukan oleh Saputra, dkk (2016) melakukan penerapan Knowledge management system (KMS) Menggunakan Teknik Knowledge Data Discovery (KDD) Pada PT PLN (Persero) WS2JB Rayon Kayu Agung. KMS ini dapat memfasilitasi para pegawai untuk mendokumentasikan pengetahuan mereka, agar dapat disimpan dan dibagi dengan pengguna lainnya, sehingga pengetahuan tersebut tidak lupa, bahkan hilang begitu saja. Serta dapat untuk mengelola reward, pencarian knowledge dan interface yang user friendly. Selain itu penelitian dilakukan oleh Nainggolan (2015) membangun Knowledge management system untuk membentuk knowledge sharing menggunakan Metode KM-Roadmap pada perguruan tinggi STTLB [6].

\section{Structural Equation Modelling (SEM)}

SEM dideskripsikan sebagai suatu analisis yang menggabungkan pendekatan analisis faktor (factor analysis), model struktural (structural model), dan analisis jalur (path analysis). Sebutan lain untuk SEM antara lain analisis struktur kovarian, analisis variabel laten, analisis faktor konfirmatori dan analisis Linier Structural Relations (LISREL). Dalam analisis SEM dapat dilakukan tiga macam kegiatan secara serentak, yaitu : [7]

1. Pengecekan validitas dan reliabilitas (berkaitan dengan analisis faktor konfir-matori)

2. Pengujian model hubungan antar variabel (berkaitan dengan analisis jalur)

3. Kegiatan untuk mendapatkan suatu model yang cocok untuk prediksi (berkaitan dengan analisis regresi atau analisis model struktural)

Terdapat banyak software SEM seperti Lisrel, Amos, EQS, dan lainnya. Lisrel merupakan program yang paling informatif dalam menyajikan hasil-hasil statistik, sehingga modifikasi model dan penyebab tidak fit atau buruknya suatu model dapat diketahui dengan mudah [8].

\section{Model Dalam SEM}

SEM memiliki dua model, yakni model struktural dan model pengukuran. Model struktural menggambarkan hubungan antara variabel laten. Parameter yang menunjukkan regresi variabel laten endogen pada variabel laten eksogen diberi label dengan huruf Yunani $\gamma$ ("gamma"), sedangkan untuk regresi variabel laten endogen pada variabel laten endogen yang lain diberi label huruf Yunani $\beta$ ("beta"). Dalam SEM, variabel laten eksogen boleh ber-"covary" secara bebas dan matrik kovarian variabel ini diberi tanda $\Phi$ ("phi") dalam huruf Yunani.

Pengguna SEM paling sering menghubungkan variabel laten dengan variabel-variabel teramati melalui model pengukuran yang berbentuk analisis faktor. Dalam model ini, setiap variabel laten dimodelkan sebagai sebuah faktor yang mendasari variabel-variabel teramati yang terkait. Faktor muatan atau loading factor yang menghubungkan variabel-variabel laten dengan variabel teramati diberi label dengan huruf Yunani $\lambda$ ("lambda"). SEM mempunyai dua matrik lamda yang berbeda, yaitu satu matrik pada sisi $\mathrm{X}$ dan matrik lainnya pada sisi $\mathrm{Y}$. Notasi lamda pada sisi $X$ adalah $\lambda \mathrm{x}$ sedangkan pada sisi $Y$ adalah $\lambda y[9]$.

\section{Tahapan Dalam Prosedur SEM}

Prosedur SEM secara umum akan mengandung tahap-tahap sebagai berikut [9]:

1. Spesifikasi model (model specification) Tahap ini berkaitan dengan pembentukan model awal persamaan struktural sebelum dilakukan estimasi. Model awal ini diformulasikan berdasarkan suatu teori atau penelitian sebelumnya.

2. Identifikasi (Identification)

Tahap ini berkaitan dengan pengkajian tentang kemungkinan diperolehnya nilai yang unik untuk setiap parameter yang ada di dalam model dan kemungkinan persamaan simultan tidak ada solusinya.

3. Estimasi (Estimation)

Tahap ini berkaitan dengan estimasi model untuk menghasilkan nilai para- 
meter menggunakan salah satu metode estimasi yang tersedia. Pemilihan metode estimasi yang digunakan ditentukan berdasarkan karakteristik dari variabel yang dianalisis.

4. Uji kecocokan (testing fit)

Tahap ini berkaitan dengan pengujian kecocokan antara model dengan data. Beberapa kriteria ukuran kecocokan atau Goodness Of Fit (GOF) dapat digunakan untuk melaksanakan langkah ini.

5. Respesifikasi (respecification)

Tahap ini berkaitan dengan respesifikasi model berdasarkan atas hasil uji ke-cocokan tahap sebelumnya.

\section{METODOLOGI}

Metodologi penelitian yang digunakan dalam penelitian ini mengadaptasi Information System Research Framework dimana dalam penelitian sistem informasi harus relevan dengan pengetahuan lingkungannya (relevance) dan patuh terhadap dasar yang ada (rigor)[10]. Hasil dalam penelitian adalah Model Knowledge management system yang teruji. Metodologi penelitian dapat dilihat pada Gambar 1.

1. Pengkajian literatur

Pengkajian literatur yaitu dapat dilihat dari sisi basis pengetahuan. Pengetahuan yang menjadi dasar pembangunan model adalah konsep mengenai perguruan tinggi, knowledge management system,dan model SEM.

2. Pengkajian aspek lingkungan
Pada aspek lingkungan dilakukan identifikasi implementasi knowledge management system dan berdasarkan riset yang telah ada. Selain itu dilakukan eksplorasi existing knowledge management system pada perguruan tinggi melalui observasi dan wawancara.

3. Identifikasi

Mengidentifikasi dan menetapkan konstruk dan elemen konstruk dalam pembangunan model beserta korelasinya.

4. Pembangunan Model

Pembangunan model merupakan proses build yang dilakukan untuk membentuk model knowledge management system pada perguruan tinggi.

5. Evaluasi model

Tahap evaluasi merupakan tahapan untuk mengevaluasi model yang telah dibangun melalui data kuesioner. Analisis data menggunakan metode SEM sehingga dihasilkan model knowledge management system pada perguruan tinggi yang telah diuji dan dibuk-tikan secara empiris.

6. Respesfikasi Model

Tahap respesifikasi model merupakan tahap yang dilakukan didasarkan atas hasil evaluasi model knowledge management system. Tahap ini akan melakukan modifikasi model sehingga model yang dihasilkan dapat diimplementasikan perguruan tinggi. 


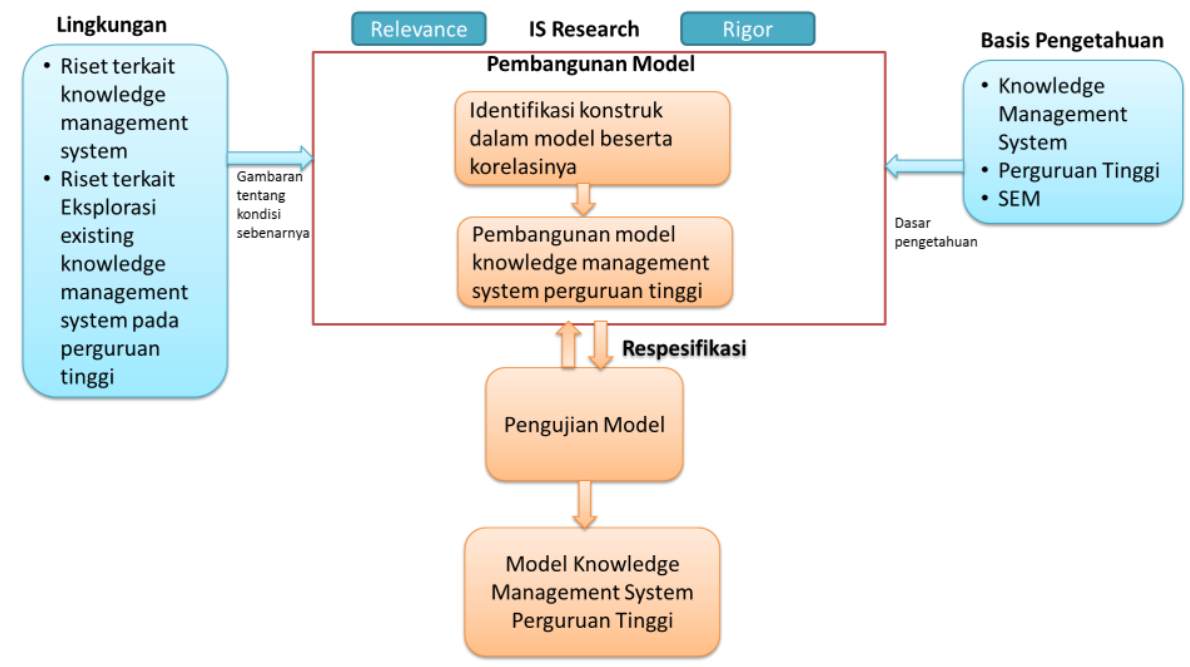

Gambar 1 Metode Penelitian

\section{PEMBAHASAN}

\section{Konstruk Model}

Berdasarkan penelitian yang telah dilakukan sebelumnya, didapatkan konstruk yang akan menjadi pembentuk model adalah sebagai berikut :

a. Regulasi

Regulasi merupakan salah satu konstruk karena regulasi dari top level management maupun pemerintah akan menjadi support faktor dalam menjalankan atau menerapkan KMS pada perguruan tinggi.

b. Knowledge management system

Knowledge management system adalah merupakan salah satu konstruk pembentuk model karena knowledge management system merupakan hal utama dalam penelitian ini. Penentuan elemen konstruk dilakukan dengan melihat komponen yang terdapat dalam KMS. Elemen konstruk KMS adalah proses, people, software. Proses merupakan elemen konstruk yang esensial sehingga memanfaatkan model SECI karena tanpa adanya suatu proses pengubahan pengetahuan dan transfer pengetahuan, pengetahuan tidak akan dapat disampaikan dari satu aktor ke aktor lainnya. People adalah aktor yang akan melakukan proses transfer pengetahuan.
Sedangkan software adalah media sistem yang akan digunakan untuk mempermudah dan mempercepat proses sha-ring pengetahuan.

c. Strategi

merupakan salah satu konstruk pembentuk model karena strategi adalah perencanaan yang akan mempermudah serta meningkatkan proses penerapan KMS yang telah ditetapkan pada perguruan tinggi sehingga diharapkan akan mendukung keberhasilan KMS tersebut.

\section{Model Knowledge management system Perguruan Tinggi}

Berdasarkan konstruk yang telah ditetapkan, dibangun model KMS perguruan tinggi. Model ini terdiri dari tiga konstruk utama yaitu regulasi, KMS, dan strategi. Model Knowledge management system perguruan tinggi dapat dilihat pada Gambar 2.

Khusus untuk konstruk KMS terdapat elemen konstruk yaitu proses, people dan software. Konstruk regulasi dan strategi merupakan hal yang akan mempengaruhi KMS. Dengan adanya pengaruh atau dukungan dari regulasi dan strategi diharapkan akan meningkatkan keberhasilan penerapan KMS. Ketiga elemen konstruk ini saling terhubung sehingga tiap elemen konstruk akan mempengaruhi elemen konstruk yang lain. 


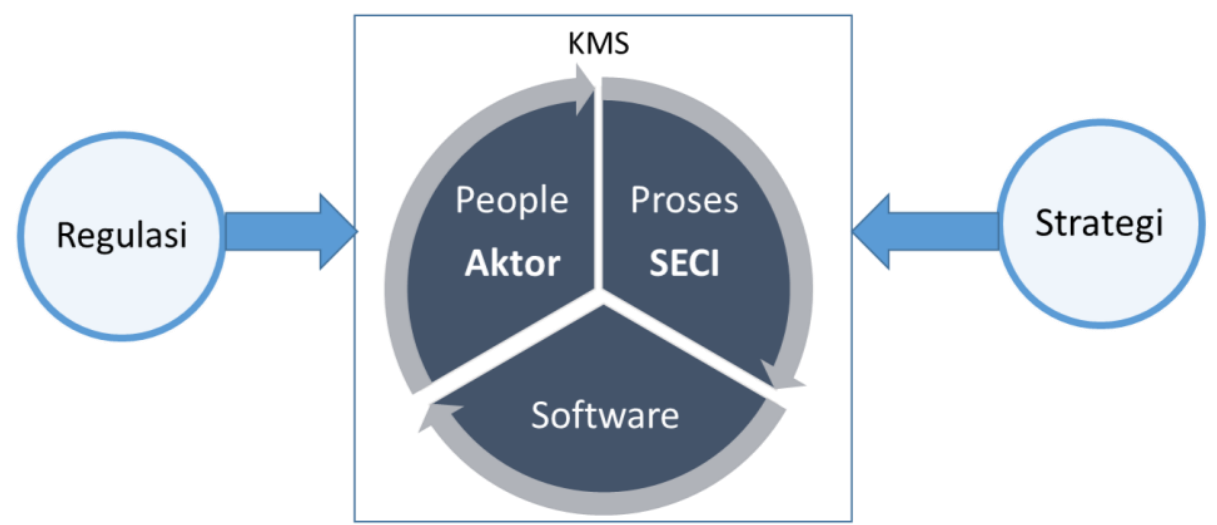

Gambar 2 Model KMS Perguruan Tinggi

Berdasarkan konstruk dan elemen konstruk model KMS perguruan tinggi dapat dibuat gambaran hubungan variabel laten dan variabel teramati yang disebut diagram alur dalam konsep SEM. Indikator dalam kuesioner dibuat ber-dasarkan elemen konstruk dan hubungan antar elemen konstruk. Dengan menggambarkan da-lam diagram alur akan memudahkan dalam pembuatan indikator atau pertanyaan kuesioner. Dalam hal ini konstruk dipetakan menjadi variabel laten dan elemen konstruk menjadi variabel teramati. Diagam alur dapat dilihat pada Gambar3. Konstruk yang akan menjadi variabel laten yaitu regulasi, KMS dan strategi.

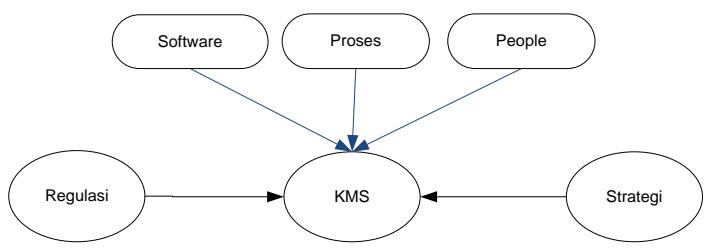

Gambar 3 Diagram alur

Variabel laten KMS mempunyai tiga variabel teramati yaitu software, proses dan people. Masing-masing variabel teramati akan diturunkan menjadi indikator atau item-item pertanyaan dalam kuesioner. Korelasi variabel laten dengan indikator apabila digambarkan dalam model SEM dapat dilihat pada Gambar 4.

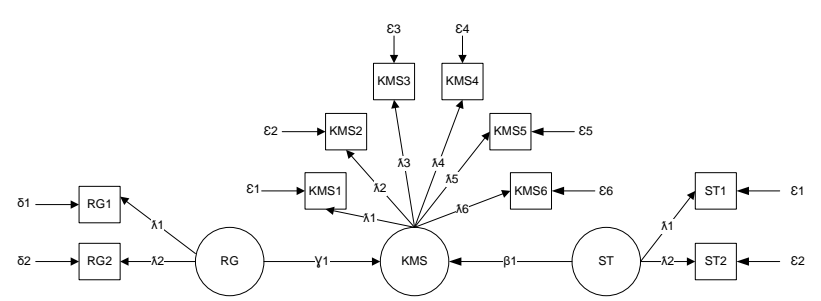

Gambar 4 Model SEM

Sedangkan hipotesis dalam penelitian ini terdiri dari dua hipotesis yaitu :

H1 : Regulasi akan berpengaruh terhadap KMS perguruan tinggi

H2 : Strategi akan berpengaruh terhadap KMS perguruan tinggi

Hipotesis penelitian dapat dilihat pada Gambar 5.

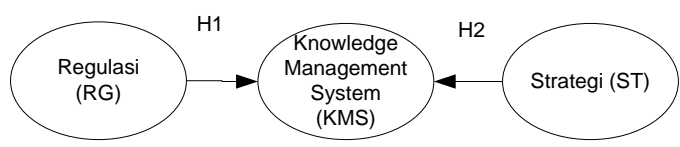

Gambar 5 Hipotesis Penelitian

\section{Pengujian Model}

Setelah pembangunan model, kemudian dilakukan pengumpulan data dan evaluasi Model. Pengumpulan data dilakukan di STIKOM Bali. Evaluasi model dilakukan dengan menggunakan SEM. Tujuan evaluasi adalah untuk menentukan validitas dan reliabilitas model pembentuk konstruk dan juga untuk menguji model yang sesuai dengan data. Tahapan dalam pengujian model dapat digambarkan yaitu Analisis statistik deskriptif, Analisis Statistik Inferensial, Analisis Model Pengukuran dan Analisis Model Struktural. Hasil akhir dari penelitian ini adalah model yang 
ditentukan ulang apabila terdapat respesifikasi untuk KMS pada perguruan tinggi.

\section{Instrumen Penelitian}

Instrumen penelitian yang digunakan adalah kuesioner. Indikator dalam kuesioner dibuat berdasarkan konstruk elemen dan hubungan antar elemen. Dalam hal ini konstruk dipetakan ke dalam variabel laten dan elemen konstruk menjadi variabel yang diamati. Variabel yang akan menjadi variabel laten yaitu regulasi, KMS, dan strategi. Kuisioner terdiri dari 10 indikator atau pertanyaan. Pertanyaan dikelompokkan berdasarkan variabel dari studi model, yang memiliki 2 indikator variabel regulasi, 8 indikator variabel KMS dan 2 indikator variabel strategi.

\section{Analisis Statistik Deskriptif}

Responden dalam penelitian ini sebanyak 115. Berdasarkan hasil pengumpulan data dari kuesioner didapatkan data demografi (identitas responden). Ilustrasi pembagian responden berdasarkan jenis kelamin dan umur dapat dilihat pada Tabel 1.

\section{Tabel 1 Demografi responden}

\begin{tabular}{|l|l|l|}
\hline Kategori & Frekuensi & Persentase(\%) \\
\hline Jenis Kelamin \\
\multicolumn{3}{|l|}{} \\
\hline Laki-laki & 67 & 58,3 \\
\hline Perempuan & 48 & 41,7 \\
\hline Total & 115 & 100 \\
\hline Umur & 20 & 17,4 \\
\hline$<25$ th & 86 & 74,8 \\
\hline $25-35$ th & 9 & 7,8 \\
\hline$>35$ th & 115 & 100 \\
\hline Total & &
\end{tabular}

\section{Analisis Statistik Inferensial}

Statistika inferensial berkenaan dengan pemodelan data dan pengambilan keputusan berdasarkan analisis data, yaitu pengujian hipotesis. Pada penelitian ini, untuk pengujian hipotesis digunakan metode pengolahan data dengan SEM. Alat bantu aplikasi komputer yang digunakan diantaranya adalah Microsoft Excel dan Lisrel 8.8. Aplikasi Microsoft Excel digunakan untuk melakukan transformasi data menggunakan Method of Successive Interval, sedangkan aplikasi Lisrel digunakan untuk analisis SEM.

\section{Analisis Model Pengukuran}

Model pengukuran adalah model yang hanya terdiri hubungan antara variabel teramati dengan variabel laten. Hubungan antara variabel laten tidak dispesifikasikan dalam model ini. Dari 115 data yang didapat dari kuesioner yang berbentuk skala likert diolah terlebih dahulu menjadi bentuk data interval agar memenuhi persyaratan perhitungan SEM yaitu multivariate normal. Untuk mengubah data Likert menjadi bentuk interval maka digunakan method of successive interval (MSI). Data hasil transformasi akan digunakan sebagai data input pada Lisrel 8.8.

\section{Identifikasi}

Tahap pertama perhitungan yang dilakukan adalah melakukan identifikasi apakah item kuesioner tersebut dapat dijadikan sebagai indikator yang baik untuk melakukan pengukuran terhadap variabel laten dalam model. Untuk menentukan variabel tersebut merupakan suatu indikator yang baik adalah dengan melihat nilai solusi standar (standardized solution) model tersebut. Untuk mencapai variabel dengan validitas yang cukup baik, variabel indikator dari model tersebut dipilih dengan nilai standardized loading factor $\geq 0.5$ dan nilai $\mathrm{t}$ muatan faktornya (factor loading) $\geq 2$ [9]. Hasil standardized loading factor berdasarkan keluaran dari program dapat dilihat pada Tabel 2. Berdasarkan pada Tabel 2 dapat disimpulkan bahwa semua indikator valid sehingga digunakan untuk perhitungan selanjutnya.

Tabel 2 Hasil standardized solution

\begin{tabular}{|l|c|l|c|l|l|l|l|}
\hline & \multicolumn{2}{|l|}{ RG } & \multicolumn{2}{l|}{ KMS } & \multicolumn{2}{l|}{ ST } & $\begin{array}{l}\text { Vali } \\
\text { ditas }\end{array}$ \\
\hline & SLF & T & SLF & T & SLF & T & \\
\hline RG1 & $\begin{array}{c}0.7 \\
3\end{array}$ & 7.71 & & & & & Baik \\
\hline RG2 & $\begin{array}{c}0.6 \\
1\end{array}$ & 6.95 & & & & & Baik \\
\hline $\begin{array}{l}\text { KMS } \\
1\end{array}$ & & & $\begin{array}{c}0.6 \\
9\end{array}$ & $\begin{array}{c}10.7 \\
1\end{array}$ & & & Baik \\
\hline $\begin{array}{l}\text { KMS } \\
2\end{array}$ & & & $\begin{array}{c}0.7 \\
3\end{array}$ & $\begin{array}{c}11.3 \\
1\end{array}$ & & & Baik \\
\hline $\begin{array}{l}\text { KMS } \\
3\end{array}$ & & & $\begin{array}{c}0.6 \\
8\end{array}$ & $\begin{array}{c}9.71 \\
\text { MM }\end{array}$ & & & Baik \\
\hline
\end{tabular}




\begin{tabular}{|l|l|l|c|c|c|c|c|}
\hline $\begin{array}{l}\text { KMS } \\
4\end{array}$ & & & $\begin{array}{c}0.7 \\
1\end{array}$ & 9.15 & & & Baik \\
\hline $\begin{array}{l}\text { KMS } \\
5\end{array}$ & & & $\begin{array}{c}0.7 \\
8\end{array}$ & $\begin{array}{c}11,3 \\
9\end{array}$ & & & Baik \\
\hline $\begin{array}{l}\text { KMS } \\
6\end{array}$ & & & $\begin{array}{c}0.7 \\
1\end{array}$ & 9.14 & & & Baik \\
\hline ST1 & & & & & $\begin{array}{c}0.8 \\
1\end{array}$ & $\begin{array}{c}13.5 \\
7\end{array}$ & Baik \\
\hline ST2 & & & & & $\begin{array}{c}0.8 \\
3\end{array}$ & $\begin{array}{c}14.1 \\
1\end{array}$ & Baik \\
\hline
\end{tabular}

\section{Uji Kecocokan Model}

Setelah melakukan identifikasi dan menentukan validitas, selanjutnya menguji kecocokan model melalui pengukuran nilai Goodness of Fit Indices (GOFI). Metode pengolahan menggunakan SEM membandingkan antara kovarian dari model konseptual yang usulkan dengan kovarian hasil pengukuran yang didapatkan dari survei. Semakin dekat perbedaan antara kovarian model dengan kovarian data, maka model tersebut akan semakin baik. Nilai GOFI yang baik menunjukkan bahwa model yang diusulkan adalah representatif terhadap data. Hasil GOFI dari keluaran program beserta keterangan kecocokan dapat dilihat pada Tabel 3.

Tabel 3 Hasil uji kecocokan keseluruhan model

\begin{tabular}{|c|c|c|}
\hline \\
\hline $\begin{array}{l}\text { Ukuran } \\
\text { GOF }\end{array}$ & $\begin{array}{l}\text { Target Tingkat } \\
\text { Kecocokan }\end{array}$ & $\begin{array}{l}\text { Tingkat } \\
\text { Kecocokan }\end{array}$ \\
\hline $\begin{array}{l}\text { Degree of } \\
\text { freedom }\end{array}$ & - & - \\
\hline Chi Square P & $\begin{array}{l}\text { Nilai yang kecil } \\
P>0.05\end{array}$ & $\begin{array}{l}\text { Kurang } \\
\text { Baik }\end{array}$ \\
\hline $\mathrm{NCP}$ & $\begin{array}{l}\text { Nilai yang kecil, } \\
\text { interval yang } \\
\text { sempit }\end{array}$ & Baik \\
\hline $\begin{array}{l}\text { Goodness-of- } \\
\text { Fit } \quad \text { Index } \\
\text { (GFI) }\end{array}$ & $\begin{array}{lr}\text { Nilai } & \text { berkisar } \\
\text { antara } & 0-1, \\
\text { dengan } & \text { nilai } \\
\text { lebih } & \text { tinggi } \\
\text { adalah } & \text { lebih } \\
\text { baik. GFI } \geq 0.9 \\
\text { adalah good fit, } \\
\text { cedanckan } 08\end{array}$ & $\begin{array}{l}\text { Kurang } \\
\text { Baik }\end{array}$ \\
\hline
\end{tabular}

\begin{tabular}{|c|c|c|}
\hline $\begin{array}{l}\text { Root Mean } \\
\text { Square } \\
\text { Residual } \\
\text { (RMR) }\end{array}$ & $\begin{array}{l}\text { Standardized } \\
\text { RMR } \leq 0.05 \\
\text { adalah good fit }\end{array}$ & $\begin{array}{l}\text { Kurang } \\
\text { Baik }\end{array}$ \\
\hline RMSEA & $\begin{array}{l}\text { RMSEA } \leq 0.08 \\
\text { adalah good fit, } \\
\text { sedang RMSEA } \\
<\quad 0.05 \text { adalah }\end{array}$ & $\begin{array}{l}\text { Kurang } \\
\text { Baik }\end{array}$ \\
\hline $\begin{array}{l}\text { Expected } \\
\text { Cross- } \\
\text { Validation } \\
\text { Index (ECVI) } \\
\end{array}$ & $\begin{array}{lr}\text { Pada } & \text { model } \\
\text { tunggal, } & \text { nilai } \\
\text { ECVI dari model } \\
\text { angka } & \text { mendekati }\end{array}$ & $\begin{array}{l}\text { Baik } \\
\text { (good fit) }\end{array}$ \\
\hline $\begin{array}{l}\text { TLI atau } \\
\text { NNFI }\end{array}$ & $\begin{array}{l}\text { TLI } \geq 0.90 \\
\text { adalah good fit, } \\
\text { sedangkan } 0.8 \leq \\
\text { TLI }<0.9 \text { adalah }\end{array}$ & $\begin{array}{l}\text { Baik } \\
\text { (marginal } \\
\text { fit) }\end{array}$ \\
\hline NFI & $\begin{array}{l}\text { NFI } \geq 0.90 \\
\text { adalah good fit, } \\
\text { sedang } 0.80 \leq \\
\text { NFI }<0.90\end{array}$ & $\begin{array}{l}\text { Baik } \\
\text { (marginal } \\
\text { fit) }\end{array}$ \\
\hline $\begin{array}{l}\text { Adjusted } \\
\text { Goodneess of } \\
\text { Fit Index } \\
\text { (AGFI) }\end{array}$ & $\begin{array}{lr}\text { Nilai } & \text { berkisar } \\
\text { antara } & 0-1, \\
\text { dengan } & \text { nilai } \\
\text { lebih } & \text { tinggi } \\
\end{array}$ & $\begin{array}{l}\text { Kurang } \\
\text { Baik }\end{array}$ \\
\hline $\begin{array}{l}\text { Relative Fit } \\
\text { Index (RFI) }\end{array}$ & $\begin{array}{lr}\text { Nilai } & \text { berkisar } \\
\text { antara } & 0-1, \\
\text { dengan } & \text { nilai } \\
\text { lebih } & \text { tinggi }\end{array}$ & Baik \\
\hline $\begin{array}{l}\text { Comparative } \\
\text { Fit } \quad \text { Index } \\
\text { (CFI) }\end{array}$ & $\begin{array}{lr}\text { Nilai } & \text { berkisar } \\
\text { antara } & 0-1, \\
\text { dengan } & \text { nilai } \\
\text { lebih } & \text { tinggi }\end{array}$ & $\begin{array}{l}\text { Baik } \\
\text { (good fit) }\end{array}$ \\
\hline $\begin{array}{l}\text { Akaike } \\
\text { Information } \\
\text { Criterion } \\
\text { (AIC) }\end{array}$ & $\begin{array}{l}\text { Nilai positif lebih } \\
\text { kecil } \\
\text { menunjukkan } \\
\text { parsimoni lebih }\end{array}$ & $\begin{array}{l}\text { Baik } \\
\text { (Good Fit) }\end{array}$ \\
\hline $\begin{array}{l}\text { Consistent } \\
\text { Akaike } \\
\text { Information } \\
\text { Criterion }\end{array}$ & $\begin{array}{l}\text { Nilai positif lebih } \\
\text { kecil } \\
\text { menunjukkan } \\
\text { parsimoni lebih }\end{array}$ & $\begin{array}{l}\text { Baik (Gooa } \\
\text { Fit) }\end{array}$ \\
\hline
\end{tabular}

Dari Tabel 3 terdapat 8 ukuran GOF yang menunjukkan kecocokan yang baik (good fit maupun marginal fit) dan 5 ukuran GOF menunjukkan kecocokan yang kurang baik, sehingga dapat disimpulkan bahwa model penelitian ini secara keseluruhan memiliki kecocokan yang baik. 


\section{Analisis Model Struktural}

Model struktural adalah model yang di dalamnya terdapat hubungan antara variabel laten. Gabungan antara model struktural dengan model pengukuran adalah suatu model SEM lengkap (full SEM). Analisis model struktural dilakukan untuk mengevaluasi koefisienkoefisen yang menunjukkan hubungan kausal atau pengaruh satu variabel laten terhadap variabel laten lainnya. Hubungan-hubungan kausal ini dinyatakan dalam bentuk hipotesis. Signifikansi suatu hipotesis dalam SEM ditentukan dengan melihat nilai estimasi dan $t$ value yang dihasilkan dari keluaran program Lisrel 8.8. Sebuah hipotesis dikatakan signifikan jika $t$-value $\geq 1.96$. Ringkasan hasil estimasi model struktural dapat dilihat pada Tabel,,,.

Tabel 4 Hasil estimasi model struktural

\begin{tabular}{|l|l|l|l|l|}
\hline $\begin{array}{l}\text { Hipotesi } \\
\text { S }\end{array}$ & Path & Estimasi & $\begin{array}{l}\boldsymbol{T} \text { - } \\
\text { value }\end{array}$ & Kesimpulan \\
\hline H1 & $\begin{array}{l}\text { RG } \rightarrow \\
\text { KMS }\end{array}$ & 0.32 & 3.59 & Signifikan \\
\hline H2 & $\begin{array}{l}\text { ST } \rightarrow \\
\text { KMS }\end{array}$ & 0.57 & 7.06 & Signifikan \\
\hline
\end{tabular}

Dari Tabel 4 dapat dilihat bahwa kedua hipotesis terbukti benar. Sesuai dengan analisis yang di-lakukan pada konstruk KMS berdasarkan literatur dan penelitian sebelumnya, hasil yang didapat menunjukkan bahwa konstruk regulasi (RG) adalah konstruk yang memiliki pengaruh terhadap KMS dengan nilai estimasi 0.32. Begitu pula dengan konstruk strategi (ST) memiliki pengaruh terhadap KMS dengan nilai estimasi 0.57. Dapat disimpulkan bahwa strategi dan regulasi merupakan faktor yang menentukan KMS. Lebih lengkap mengenai analisis terhadap hasil estimasi dapat dilihat pada Tabel 5.
Tabel 5 Hasil pembuktian hipotesis

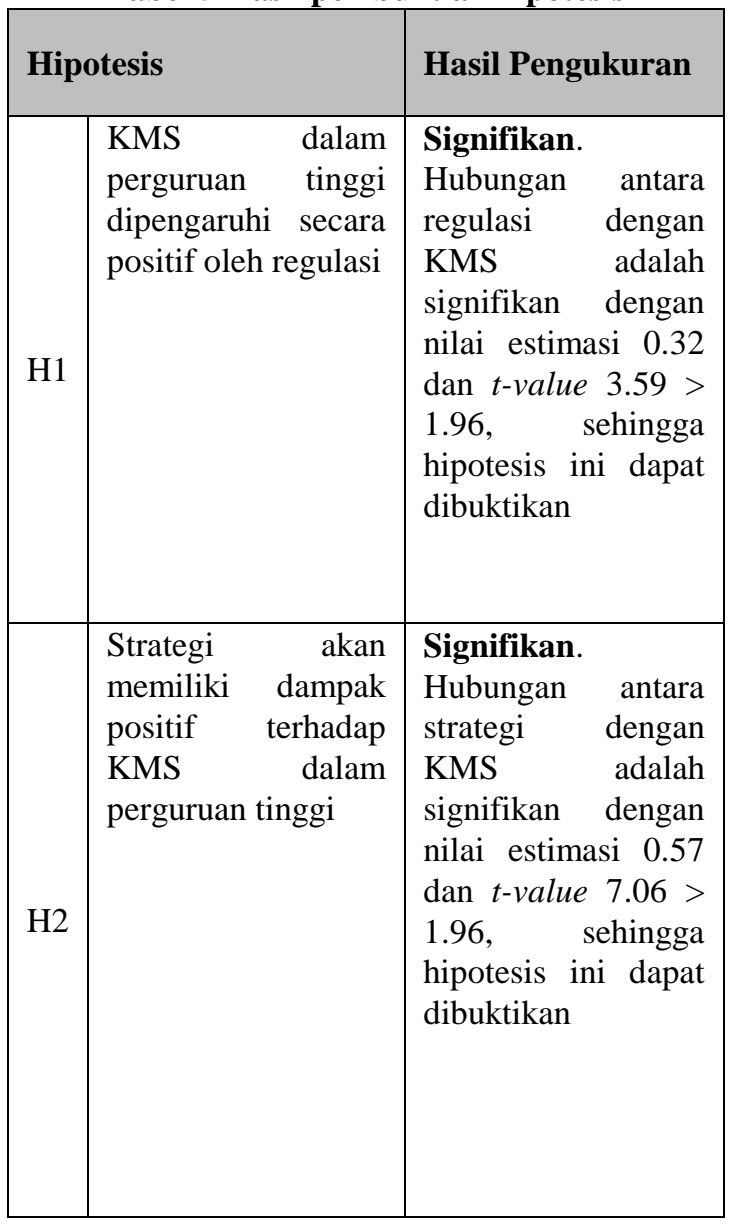

Proses respesifikasi dilakukan apabila model yang diperhitungkan tidak memberikan nilai kecocokan, validasi dan reliabilitas yang baik. Respesifikasi dilakukan dengan menghilangkan variabel, menambahkan hubungan antara error dalam variabel. Hal ini dilakukan sampai hasil perhitungan model memberikan nilai kecocokan, validitas dan reliabilitas yang baik. Berdasarkan hasil pengukuran, semua pengukuran memberikan hasil yang baik sehingga tidak dilakukan respesifikasi model. Model KMS pada perguruan tinggi sesuai dengan Gambar 2.

\section{SIMPULAN}

Model KMS pada perguruan tinggi terdiri dari tiga konstruk yaitu regulasi, KMS dan strategi. Pada konstruk KMS, terdapat elemen konstruk yaitu proses, people dan software. Penelitian ini telah mengevaluasi 
model KMS pada perguruan tinggi. Hasilnya menunjukkan bahwa regulasi dan strategi memiliki pengaruh signifikan terhadap KMS. Berdasarkan hasil evaluasi, maka model respesifikasi sama dengan model KMS awal.

\section{DAFTAR PUSTAKA}

[1] A. Tiwana. The Knowledge Management Toolkit, New Jersey : Prentice Hall, 2000.

[2] Deallenbach, H.G., (1995), "Systems and Decision Making: a Management Science Approach", John Willey \& Sons.

[3] Nur, P.L.F., Sensuse, D.I., Handoko, D. (2010). "Model Knowledge Management System Pada Lembaga Riset Berbasis Semantic Web Dan Web 2.0", Journal of Information System, vol 6(2), 85-93.

[4] Sundari, J. (2014). Knowledge management system Berbasis Website Pada Instalasi Elemen Bakar Eksperimental PTBN Serpong Tangerang Selatan. Jurnal Pilar Nusa Mandiri. X(1), 21-30

[5] Safriadi, N., Salam, U., Hazriani, R. (2015). Wikipeat Sebagai Implementasi Knowledge management system (KMS) Untuk Pengelolaan Hasil Penelitian di Universitas Tanjungpura. Jurnal Edukasi dan Penelitian Informatika (JEPIN). 1(1), 37-40.

[6] Saputra, N.E., Tania, K.D., Heroza, R.I. (2016). Penerapan Knowledge management system (KMS) Menggunakan Teknik Knowledge Data Discovery (KDD) Pada PT PLN (PERSERO) WS2JB Rayon Kayu Agung. Jurnal Sistem Informasi (JSI). 8(2), 10381055

[7] Sugiyono (2011) : Statistika untuk Penelitian, Bandung: Alfabeta.

[8] Ghozali, I. dan Fuad (2008). Structural Equation Modeling - Teori, Konsep dan Aplikasi dengan Program Lisrel 8.80, Semarang: Badan Penerbit Universitas Diponogoro.

[9] Wijanto, S.H. (2008) : Structural Equation Modeling dengan LISREL 8.8, Yogyakarta: Graha Ilmu.

[10] Hevner, A. C., March, S., Park, J., dan Ram, S. (2004) : Design Science in Information Systems Research,
Management Information Systems Quarterly, 28(1), 77-105. 